Research Article

\title{
Deformation Fields Measurement of Crack Tip under High-Frequency Resonant Loading Using a Novel Hybrid Image Processing Method
}

\author{
Hongli Gao $(\mathbb{D}$, Zhaonian Zhang, Wei Jiang, Kaiyong Zhu, and Ao Gong \\ College of Mechanical Engineering, Zhejiang University of Technology, Hangzhou, Zhejiang 310014, China \\ Correspondence should be addressed to Hongli Gao; ghl_zjut@126.com
}

Received 4 December 2017; Revised 10 April 2018; Accepted 16 April 2018; Published 3 June 2018

Academic Editor: Chao Tao

Copyright (c) 2018 Hongli Gao et al. This is an open access article distributed under the Creative Commons Attribution License, which permits unrestricted use, distribution, and reproduction in any medium, provided the original work is properly cited.

\begin{abstract}
A novel hybrid image processing method is proposed to obtain the crack tip location, crack propagation path, displacement, strain fields, and plastic zone size of crack tip region under high-frequency resonant loading in this paper. An ordinary CCD camera is used to collect a series of crack images on one side of the compact tension (CT) specimen; meanwhile, a high-speed digital camera is used to acquire a series of digital speckle images of the other side of the specimen under the loading conditions at regular time intervals. Digital image processing (DIP) method is used to determine the macroscopic crack position. Digital image correlation (DIC) method is applied to obtain the displacement, strain fields, and plastic zone size of crack tip region. The characteristic digital speckle images of one stress cycle are obtained by data fitting and image matching method. Accordingly, the displacement/strain fields of crack tip region within one stress cycle and the displacement and strain amplitude fields with different crack lengths are obtained and analyzed. The obtained results are compared with the measured results of ordinary methods and show a good match. The success of this method will help to obtain better insight into and understanding of the fatigue and failure behavior of metal material with mode I crack under high-frequency resonant loading.
\end{abstract}

\section{Introduction}

In general, fatigue failure is the major failure mode of the metal mechanical parts. Fatigue cracks initiation and propagation in the metal materials or structures occur when they are subjected to alternating load and can result in material fatigue failure. Many studies show that a large number of fractures are closely related to the generation and propagation of fatigue cracks [1-3]. Nowadays, the fatigue failure cannot be completely studied by the effective theoretical method, so the specific material fatigue crack growth (FCG) tests have acquired considerable importance for studying the fracture mechanism. They have great significance for improving the reliability and service life of mechanical products $[4,5]$. The most common cracks generated in the practical engineering structures belong to mode I cracks which are the most dangerous crack type. The FCG tests using the CT specimens with mode I precrack are often applied to study the material fatigue characteristics.
Electromagnetic resonant FCG testing system is a test device for determining the fatigue characteristics of the metal materials and their components under high-frequency resonant loading based on resonance principle. Due to its high working frequency, low energy consumption, short testing time, and good test waveform, it is widely used in mechanics labs for material fatigue test. And it is also an indispensable test device applied to test some performance of specimen or component under resonance state [6-9]. In the test, specimen vibrates at high speed under the high-frequency resonant loading; the high-speed movement of specimen results in the inertial effect and stress wave propagation effect [10-12], which make the theoretical calculation of specimen deformation fields complicated. This paper presents a method based on the combination of DIP, DIC, and digital high-speed photography techniques to measure the displacement, strain fields, and further plastic zone size of crack tip region under high-frequency resonant loading. 
DIC method is a noninterference and noncontact precise optical measurement method developed in recent years to measure the global displacement and strain fields of the forced body based on digital image processing and numerical computing [13-15]. In numerous literature actually the same technique has been given different names, such as digital speckle correlation method (DSCM) [13]. Compared with the other optical techniques used for in-plane deformation measurement, such as holographic interferometry [16], Moire interferometry [17], and laser speckle photography [18, 19], the DIC method has some special advantages which are simple experimental setup and specimen preparation, low requirements in measurement environment, wide range of measurement sensitivity and resolution, and automatic realtime measurement and analysis. So, the DIC method is very suitable for measuring the specimen deformation fields under cyclic loading.

At present, the DIC methods of static and quasi-static material test have been more mature. And the DIC method of high-speed photography for transient impact test has also made some achievements in recent years [20,21]. The highspeed digital camera can be used for both the material fatigue test and material impact test. Acquiring images in material impact test is very simple. But for the material fatigue test, acquiring images is more complicated, because the testing time of fatigue test is very long and the test load changes rapidly. In order to study the variation law of displacement and strain fields of specimen in fatigue test, the digital speckle images of specimen at the characteristic load values within one stress cycle, such as the maximum, minimum, and average load values, must be obtained. The literatures [22, 23] adopted the stroboscopic illumination methods implemented by keeping the load, CCD, and stroboscopic light in strict synchronization in the low-frequency fatigue test. But the testing frequency of high-frequency resonant FCG test can reach more the $100 \mathrm{~Hz}$; in this case, it is almost impossible to keep load, CCD, and stroboscopic light in strict synchronization. In this paper, first, a high-speed digital camera is used to acquire a series of digital speckle images of the CT specimen for a short period of time under high-frequency sinusoidal alternating load at regular intervals; then DIC method is applied to obtain the displacement, strain fields, and further plastic zone size of crack tip region, and the characteristic load points images of one stress cycle are obtained by leastsquare sinusoidal fitting and image matching method.

At present, many researchers use DIC method to measure the deformation fields of crack tip and further study material fracture characteristics and predict fatigue life [20-24]. The measurement of fatigue crack tip deformation fields essentially belongs to the measurement of dynamic discontinuous deformation fields. There are two common methods used to solve this problem: one is the extended DIC method [25-27], and the other is the continuous DIC method [14] which is very mature today. Using the former method to measure the deformation fields of the crack tip under highfrequency resonant loading, the algorithms are very complex and the generated data is very huge, so it is difficult to meet the requirements of online measurement of crack tip deformation fields. In the latter method, the discontinuous regions (cracks, defects, etc.) are eliminated first, and the displacement and strain fields at the remaining crack tip region are calculated by the continuous region DIC method. However, the fatigue crack grows continuously, and the discontinuous region (crack region) changes continuously. If you want to use this method in the FCG test, it is necessary to determine the fatigue crack position first. So in this paper a novel hybrid image processing method is proposed. The DIP method is used to determine the macrocrack path, length, and tip position. The DIC method is applied to obtain the displacement, strain fields, and plastic zone size of crack tip region based on the results of DIP operation. The DIP methods used to measure the crack tip position and crack propagation path are direct, concise, and accurate [28-30] but cannot be used to determine the displacement and strain fields at the crack tip region. With the combination of DIP and DIC methods, the macroscopic location of the crack and the microscopic deformation fields at the crack tip region can be determined simply and accurately. The research results can be a theoretical foundation for further research on the fatigue crack propagation mechanism and the parameter measurement method in the crack propagation under high-frequency resonant loading.

\section{Measuring System}

2.1. Overview of the Method. The block diagram of the image acquisition and processing is shown in Figure 1, including the acquisition of specimen speckle images and corresponding crack images, the detection of crack length and crack tip position based on DIP method, the determination of displacement and strain fields of crack tip region based on DIC method, the determination of shape and size of plastic zone at crack tip region based on the DIP operation results and the DIC deformation fields data, the determination of speckle images corresponding to characteristic load values based on least-squares sinusoidal data fitting and image matching method, the determination and analysis of crack tip deformation fields at characteristic load values within one stress cycle, and the determination of deformation amplitude fields of crack tip region with different crack lengths.

2.2. Measuring System Components and Image Acquisition. The system components shown in Figure 2 are an electromagnetic resonant high-frequency fatigue tester (PLG-100) with the load controller, which performs the operations of applying the sinusoidal alternating load to the CT specimen, tracking the system natural frequency, and controlling the test load, a high-speed digital camera, an ordinary CCD camera, light sources, an image acquisition controller, and a computer. The high-speed digital camera is the Phantom V341 produced by VRI company with the frame rate range from 800 to $61800 \mathrm{fps}$ and the image resolution range from $256 \times 84$ to $2560 \times 1600$ pixels, meeting the requirements of the measurement of displacement and strain fields at the crack tip region of the CT specimen as shown in Figure 3. The ordinary CCD camera is the large area array industrial camera CameraLink 22M04 of Pantera produced by Canada DALSA Company, with the resolution of $5344 \times 4008$ pixels, 


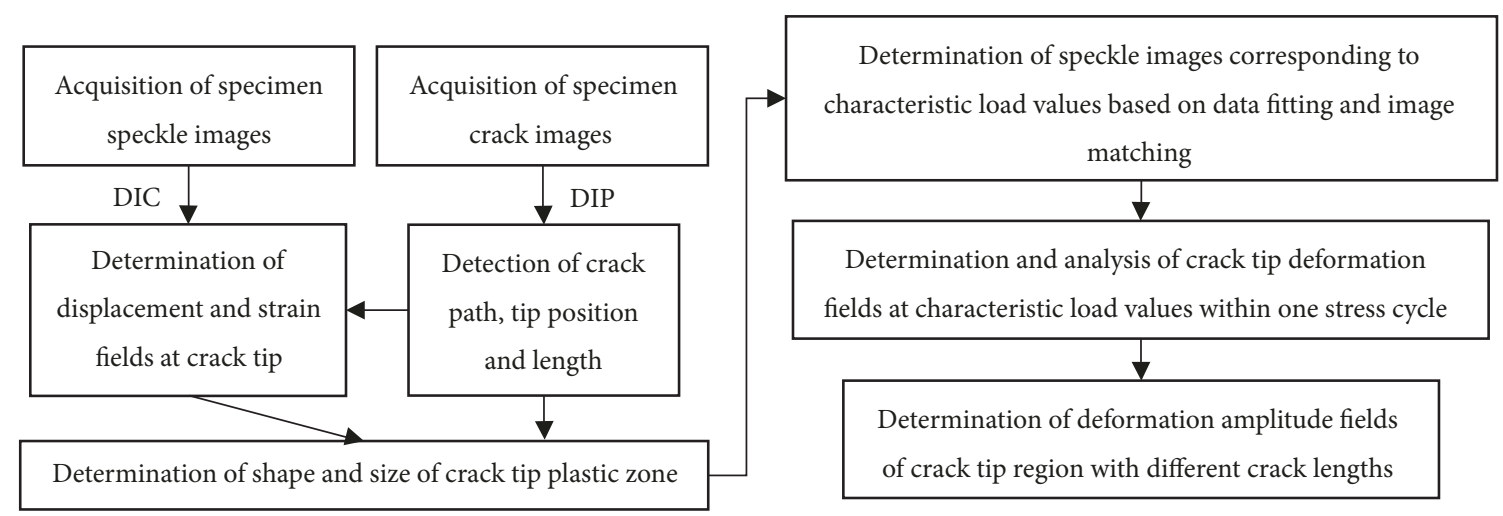

FIGURE 1: The block diagram of the proposed measuring method.

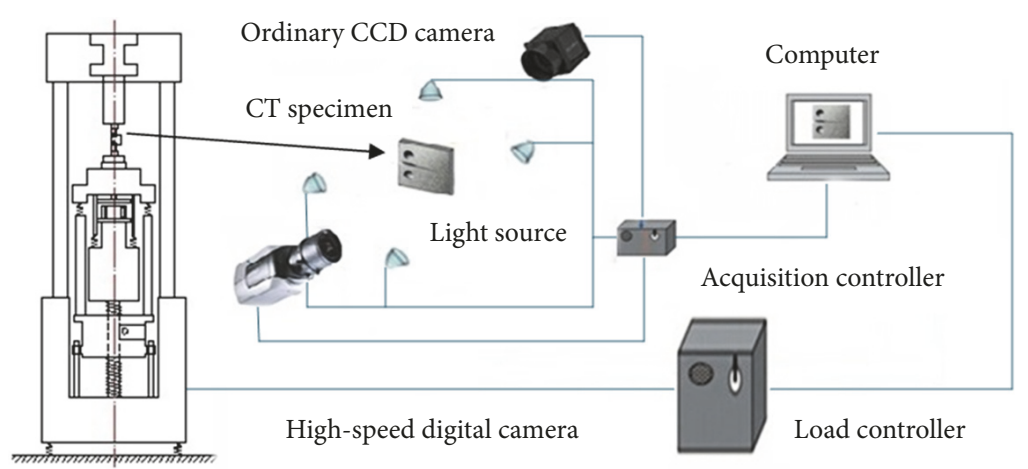

High-frequency resonant fatigue tester

FIGURE 2: The proposed measuring system of crack tip deformation fields under high-frequency resonant loading.

pixel size of $9 \mu \mathrm{m} \times 9 \mu \mathrm{m}$, and frame rate of $135 \mathrm{fps}$. The lens is the macro lens with megapixel which matches the camera and the maximum magnification is 1.0. The calibration value of this crack length measuring system is $0.00949 \mathrm{~mm} /$ pixel.

Some resonant FCG tests with CT specimens of different metal materials have been carried out on the experimental setup as shown in Figure 2. The experimental results show that the resonant frequency of the system is from $90 \mathrm{~Hz}$ to $135 \mathrm{~Hz}$ in the stable crack propagation stage. Considering enough information extraction, data storage space, and computer processing capacity, the frame rate of the highspeed camera is set to $3180 \mathrm{fps}$, and the corresponding CCD image resolution is $1280 \times 720$ pixels. In this case, around 24 35 speckle images are collected within one stress cycle. Under the control of the image acquisition controller, the high-speed camera acquires a series of digital speckle images in a short period of time under high-frequency sinusoidal loading at regular intervals. Meanwhile the ordinary CCD camera collects corresponding crack image on the other side of specimen and transfers it to the computer to determine the crack position online. For most metal materials, the FCG rate is not too fast even in the high-frequency FCG test, so the crack length and crack tip position can remain stable within the period of time. Figure 3 shows the geometry, acquired crack image, and digital speckle image of the used CT specimen.
2.3. Matching the Speckle Images of Specimen under HighFrequency Resonant Loading. Uniaxial resonant fatigue testing machine is a linear vibrating system with multiple degrees of freedom (MDOF). According to the theory of linear MDOF vibration system, the applied specimen in the FCG test will undergo sinusoidal vibration with the same frequency as the exciting force. In the stable FCG stage, the displacement of any point in the crack tip elastic region is a sinusoidal variable with the same frequency as the applied load. The digital speckle images of specimen are collected, and then their displacement fields of crack tip region are calculated. A point in the crack tip elastic region is taken as the feature point, and a series of displacement values of the feature point are extracted from the displacement fields and then fitted by the least-square sinusoidal fitting method to obtain the fitted sine curve. The main process is as follows.

$\mathrm{N}$ displacement values of the feature point $\mathrm{Y}(i)(i=1,2,3$, $\ldots, n)$ are used for sine curve fitting. The fitting function is given by

$$
g\left(t_{i}\right)=A \sin \left(2 \pi f t_{i}+\phi\right)
$$

where $A$ is the amplitude, $\phi$ is the initial phase, and $f$ is the frequency as a known parameter which equals the exciting force frequency. 

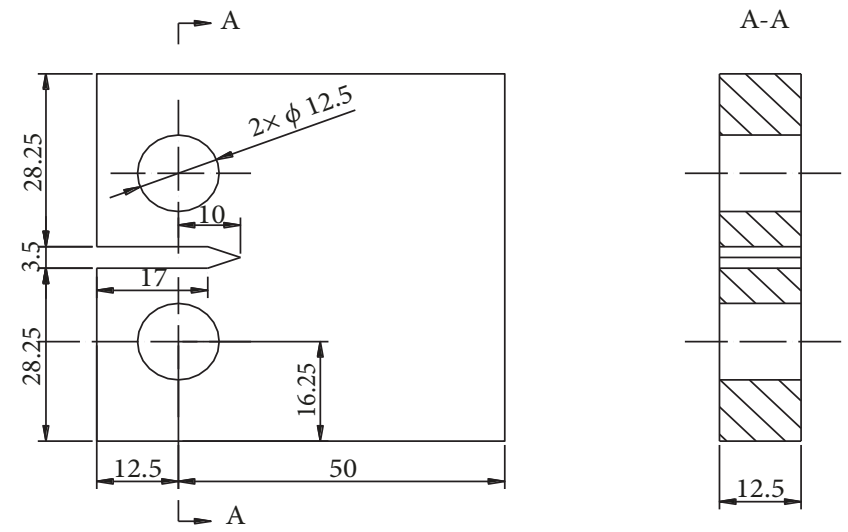

(a)

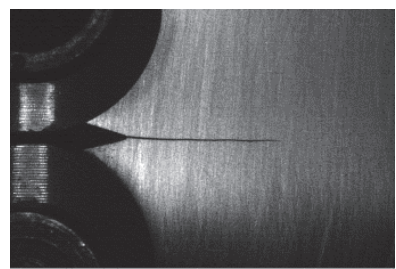

(b)

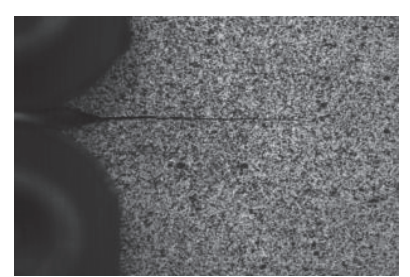

(c)

FIGURE 3: (a) Geometry of CT specimen. (b) Crack image of CT specimen. (c) Digital speckle image of CT specimen.

Based on the sampling frequency $f_{\mathrm{v}}$, sampling time $t_{i}=$ $i \cdot \Delta t=i / f_{\mathrm{v}}(i=1,2, \ldots, \mathrm{n})$, and angular frequency $w=$ $2 \pi f / f_{\mathrm{v}}$, so (1) is expressed as discrete form

$$
g(i)=A \sin (w i+\phi) .
$$

Equation (2) can be converted to

$$
g(i)=a \sin (w i)+b \cos (w i),
$$

where $a=A \cos (\phi)$ and $b=A \sin (\phi)$.

The sum of squared errors is defined as the evaluation function, as shown in

$$
\xi=\sum_{i=0}^{n-1}[Y(i)-a \sin (w i)-b \cos (w i)]^{2} .
$$

Three matrices are constructed as

$$
\begin{aligned}
& M=\left[\begin{array}{cc}
\sin (w) & \cos (w) \\
\ldots & \ldots \\
\sin (w n) & \cos (w n)
\end{array}\right], \\
& x=\left[\begin{array}{l}
a \\
b
\end{array}\right], \\
& y=\left[\begin{array}{c}
Y(1) \\
\ldots \\
Y(n)
\end{array}\right] .
\end{aligned}
$$

The solution of least-square of equation (4) is as follows:

$$
\begin{aligned}
& x=\left(M^{T} M\right)^{-1}\left(M^{T} y\right), \\
& A=\sqrt{a^{2}+b^{2}}, \\
& \phi=\arctan \left(-\frac{b}{a}\right) .
\end{aligned}
$$

After the least-squares sinusoidal fitting of the displacement values of the feature point, the fitted displacement sine curve and the corresponding speckle images are matched to obtain the speckle images corresponding to the characteristic load values within one stress cycle, such as the maximum, minimum, and average load values.

\section{Measuring Algorithms Based on Image Processing Methods}

3.1. DIP Measuring Algorithms. DIP measuring algorithms include fatigue crack initiation point detection algorithm, crack outline extraction algorithm, and fatigue crack path and length determination algorithm.

3.1.1. Fatigue Crack Initiation Point Detection Algorithm. As shown in Figure 3(a), the CT specimen precrack vertex, which is the intersection point of two regular machined edges, is the initiation point of the fatigue crack. First, the precrack region is obtained by template matching, then Harris corner extraction method is used to detect corners, and the subpixel positions of the corners are determined as shown in Figure 4, where the red dots represent the subpixel 


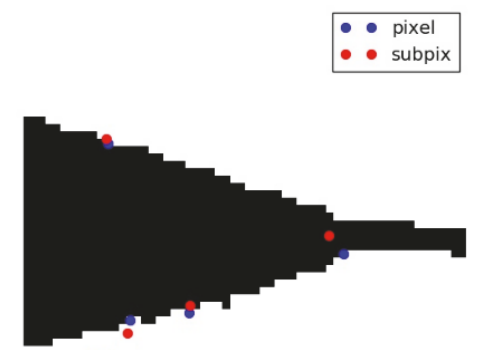

FIGURE 4: Subpixel positions of corners at the matched precrack region.

positions of the corners at the matched precrack region, and the rightmost red dot is the initiation point of the fatigue crack.

3.1.2. Crack Outline Extraction Algorithm. This algorithm has been applied to locate the subimages which contain the crack according to the subimages grayscale standard deviation(GSD) distribution and extract the crack outline from the subimages using a maximum entropy threshold segmentation method. The fatigue crack grows almost along horizontal direction from the precrack vertex because of the loading condition and precrack direction. Select the narrow rectangle area including fatigue crack from the crack initiation point to the right edge of the crack image as region of interest (ROI) and then divide the ROI into two rows of square subimages with same size as shown in Figure 5(a). The lower row subimages contain the fatigue crack; the upper row subimages only contain the background. Calculate the GSD values of each subimage as shown in Figure 5(b), where the GSD values of background subimages fluctuate slightly from the fatigue crack initiation point to the right specimen edge. However, the GSD values of crack subimages change rapidly, the value of the subimage at the beginning position of the crack is very big, and then the values become smaller until becoming equal to the corresponding background subimage GSD values. If GSD values of two corresponding subimages in one column are approximately equal, that indicates the fatigue crack does not reach this subimage region yet.

The subimage GSD value $\sigma$ can be calculated by (7), where $n$ is the total number of image pixels, $r_{i}$ is the ith grey level, $i=0,1,2, \ldots, L-1, n_{i}$ is the number of pixels corresponding to the grey level $r_{i}, P\left(r_{i}\right)=n_{i} / n$ is the normalized grayscale histogram, and $m$ is the grayscale average value.

$$
\sigma=\sqrt{\sum_{i=0}^{L-1}\left(r_{i}-m\right)^{2} p\left(r_{i}\right)}=\sqrt{\frac{\sum_{i=0}^{L-1}\left(r_{i}-m\right)^{2} n_{i}}{\sum_{i=0}^{L-1} n_{i}}}
$$

A maximum entropy threshold segmentation method is used to segment the first 9 subimages containing the crack to obtain a crack binary image with noise. Then a clean crack binary image as the crack outline is obtained by removing small connected areas.
3.1.3. Fatigue Crack Path and Length Determination Algorithm. For convenience in determining the crack path, length, and crack tip position, a single pixel skeleton image is extracted from the crack outline image by morphological thinning algorithm and then the burrs of the crack skeleton are removed. The crack skeleton represents the center line of the crack and can be viewed as fatigue crack path. And then the crack length and crack tip position can be determined from the fatigue crack path. In this paper, two types of crack length have been calculated, one is the straight-line length from the crack initiation point to the crack tip, and another one is the real crack length determined from the 8-direction chain code of the fatigue crack path. Figure 6 shows the result images in the process of crack extraction.

\subsection{DIC Measurement Algorithms of Crack Tip Displacement} and Strain Fields. In order to determine the displacement fields of crack tip region, two images of the CT specimen surface coated with artificial speckle pattern are compared: one is called reference image before deformation and the other is called target image after deformation. In this experiment, the reference image has been collected before loading, and the target image has been collected during the FCG test in a short period of time at regular intervals. In the reference image, a red rectangle region $(12 \mathrm{~mm} \times 8 \mathrm{~mm})$ including a portion of crack from the tip which has been determined in the target image based on the proposed DIP method is chosen as ROI to calculate the displacement and strain fields, where a yellow strip $(3 \mathrm{~mm} \times 1 \mathrm{~mm})$ surrounding the crack is chosen as the invalid region, as shown in Figure $7(a)$. Figure $7(b)$ is the target image which contains fatigue crack.

In the ROI, a white rectangle region is selected as the subset with the size of $39 \times 39$ pixels. Then in the target image, the inverse compositional Gauss-Newton method [31] is used to determine the subpixel displacement, which searches for the extreme point of correlation coefficient to locate the corresponding subset in the target image. In the FCG test, the applied specimen has deformation of translation, tensile, and shear, so the first-order shape function

$$
\begin{aligned}
& C_{Z N S S D} \\
& =\sum_{x=-M}^{M} \sum_{y=-M}^{M}\left[\frac{f(x, y)-f_{m}}{\sqrt{\sum_{x=-M}^{M} \sum_{y=-M}^{M}\left[f(x, y)-f_{m}\right]^{2}}}\right. \\
& \left.-\frac{g\left(x^{\prime}, y^{\prime}\right)-g_{m}}{\sqrt{\sum_{x=-M}^{M} \sum_{y=-M}^{M}\left[g\left(x^{\prime}, y^{\prime}\right)-g_{m}\right]^{2}}}\right]
\end{aligned}
$$

can be used to describe the shape of image subset after deformation. In this paper, zero-normalized sum of squared differences (ZNSSD) function [13] is selected as the correlation function which is insensitive to fluctuation of illumination source and has small error, as shown in (8), where $f(x, y)$ is the grayscale value at the point $(x, y)$ in the subset of the reference image; $g\left(x^{\prime}, y^{\prime}\right)$ is the grayscale value at the point 


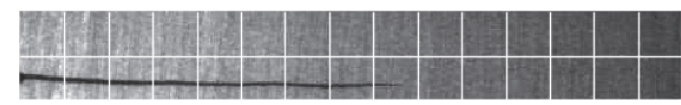

(a)

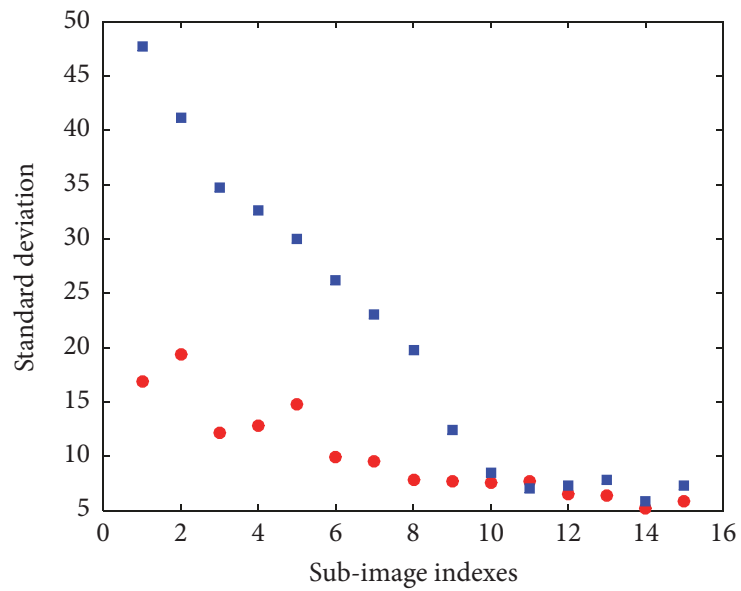

- upper

- lower

(b)

FIGURE 5: (a) Division of subimages. (b) Distribution of the subimages grayscale standard deviation.

$\left(x^{\prime}, y^{\prime}\right)$ in the subset of the target image; $f_{m}$ and $g_{m}$ are the average grayscale values of the subsets in the reference image and the target image, respectively.

After the displacement field is obtained, the strain field can be directly calculated by differentiation of the displacement field data. In order to reduce the noise, the GreenLagrangian strain tensor is used to describe strain and local least-squares fitting technique [31] is used to estimate the strain. In this paper the open source software NCORR [31] based on MATLAB has been used to calculate the displacement and strain fields at the crack tip region of CT specimen.

3.3. Determination of Crack Tip Plastic Zone Based on DIC. There are always different degrees of plasticity in metal materials. When an elastic-plastic body with crack is subjected to load, the crack tip will produce a plastic zone. J M VascoOlmo [32] used DIC technique to quantitatively characterize the shape and size of the plastic zone at the crack tip of pure titanium. Firstly, the displacement and strain fields of crack tip region are obtained by DIC method, and the stress field is obtained according to generalized Hooke law. In the crack tip elastic zone the stress field is accurate, but in the plastic zone the stress field is too large due to the existence of plastic deformation. But in this case the elastic zone surrounds the plastic zone, and their stress field boundary is clear. Then the equivalent stress field is calculated based on the Von Mises yield criterion. Finally, the shape and size of the plastic zone at the crack tip are obtained by connecting the points whose equivalent stress values equal yield stress value of the material itself.

\section{Results and Discussions}

In this section, in order to measure the deformation fields of crack tip region under high-frequency resonant loading, a batch of CT specimens of $45^{\#}$ steel are used to carry out the FCG test in the experimental setup as shown in Figure 2. The size of CT specimen is shown in Figure 3(a). The applied test loading parameters are $F_{\text {max }}=15.2 \mathrm{kN}, F_{\text {min }}=8.8 \mathrm{kN}$, and $F_{m}=12 \mathrm{kN}$. And the load frequency is the system resonant frequency which changes with the fatigue crack length and can be determined online. The major steps of resonant FCG test are installing the CT specimen, applying the static load to the specimen, searching for the systemic initial resonant frequency, setting the dynamic test loading parameters, and performing the FCG test.

4.1. Measurement Results and Verification of Crack Length. A series of crack images are collected during the FCG test using ordinary CCD camera, and then the crack paths are obtained by the proposed DIP method in Section 3.1. Figure 8 shows the five crack images with different crack lengths and related result images. In order to verify the measuring accuracy of crack length and crack tip position, the obtained results are compared with the measurement results using the optical microscope with the accuracy of $0.001 \mathrm{~mm}$. The FCG test and the crack length measurement using optical microscope are carried out independently. In the FCG test, the crack lengths (straight-line crack length and real crack length) and the crack tip position are calculated by online measuring method based on DIP. After a period of time, the machine is stopped and the test is interrupted, then the specimen is removed 


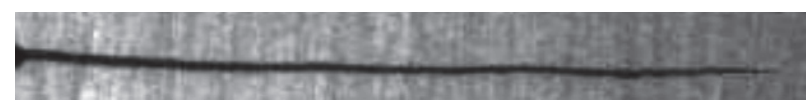

(a)

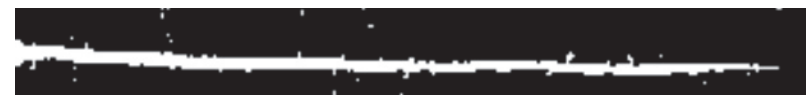

(b)

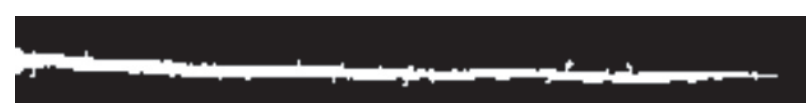

(c)

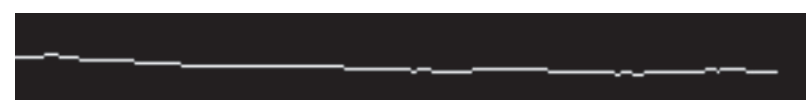

(d)

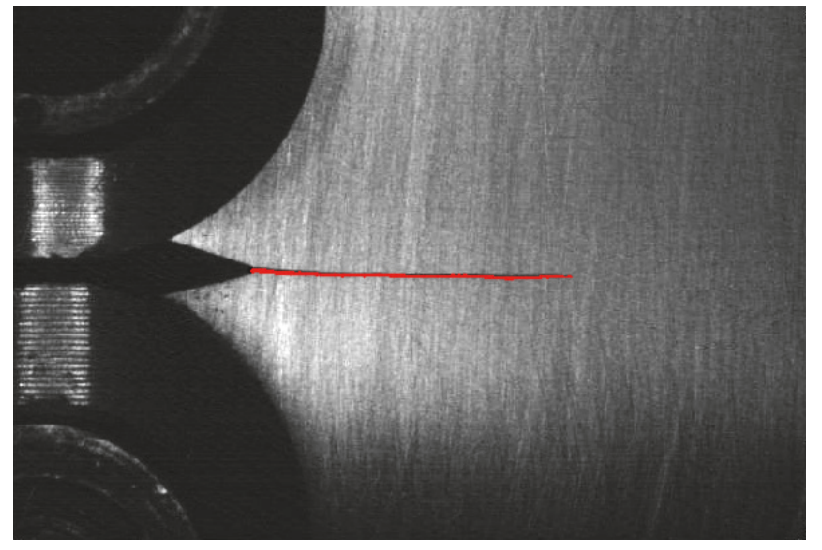

(e)

FIGURE 6: Result images in the process of crack extraction. (a) Original crack; (b) crack binary image with noise; (c) clean crack binary image; (d) single pixel skeleton image; (e) actual detected crack in the CT specimen.

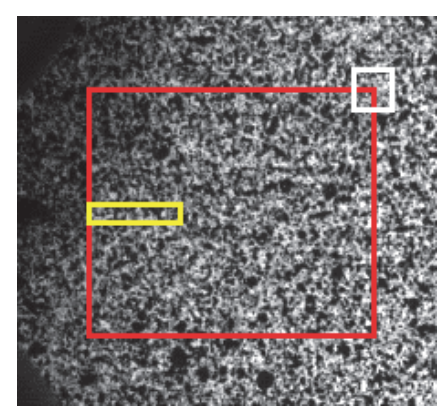

(a)

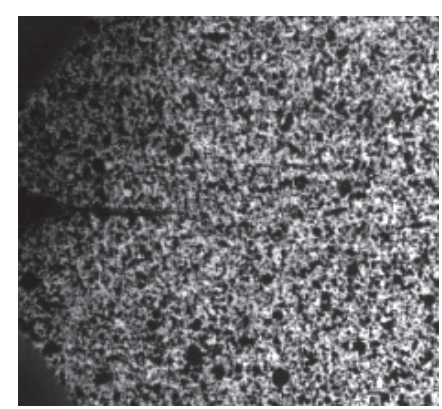

(b)

Figure 7: (a) The ROI in the reference image; (b) target image.

from the test machine, and the straight-line crack length and the crack tip position are determined again by using a microscope. The comparative data of the straight-line crack lengths are shown in Table 1, and the relative error is shown in Figure 9. The comparison of the cracks tip positions obtained by the two methods is shown in Figure 10, where the upper left corner point of the specimen is taken as the coordinate origin. As can be seen from Table 1, the measurement results of straight-line crack lengths obtained by the two methods are in good agreement, verifying that it is feasible to measure the crack length by proposed DIP method. In Figure 9, when the cracks are shorter, the relative errors are larger and then decrease. The smaller cracks are not obvious compared to the background image, so the error occurs easily. As can be seen 

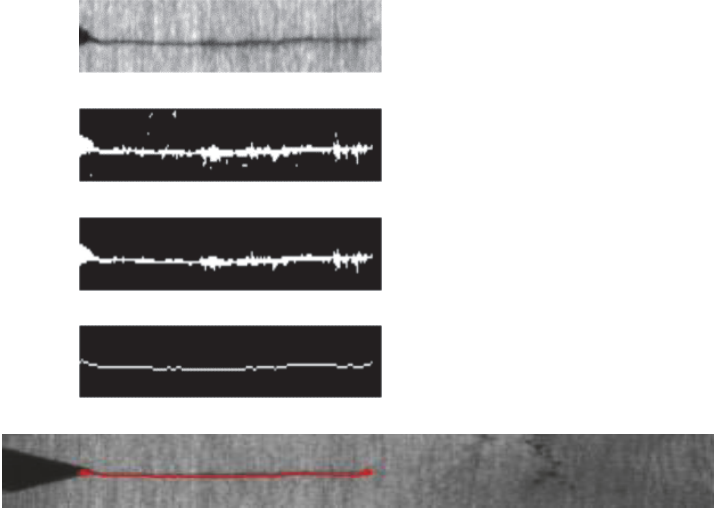

(a) Two kinds of crack length: $9.94 \mathrm{~mm}$ and $10.96 \mathrm{~mm}$
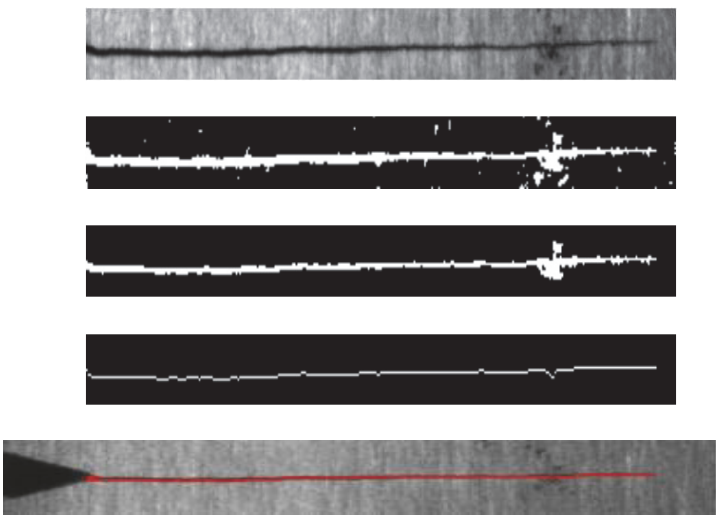

(c) Two kinds of crack length: $17.63 \mathrm{~mm}$ and $19.06 \mathrm{~mm}$
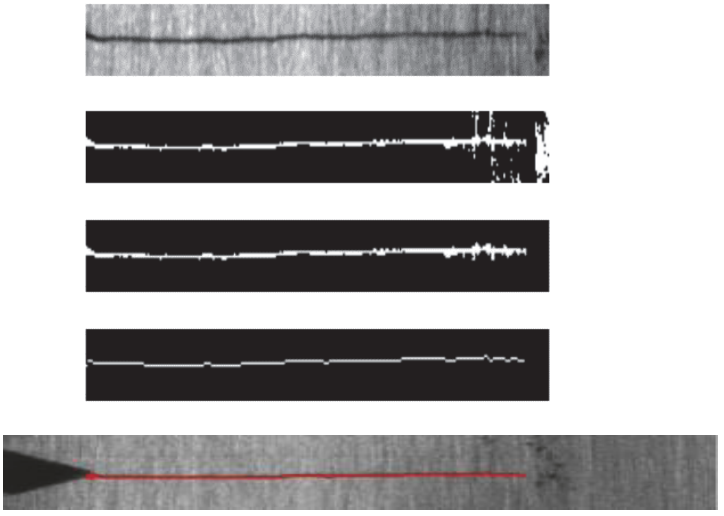

(b) Two kinds of crack length: $15.13 \mathrm{~mm}$ and $15.96 \mathrm{~mm}$
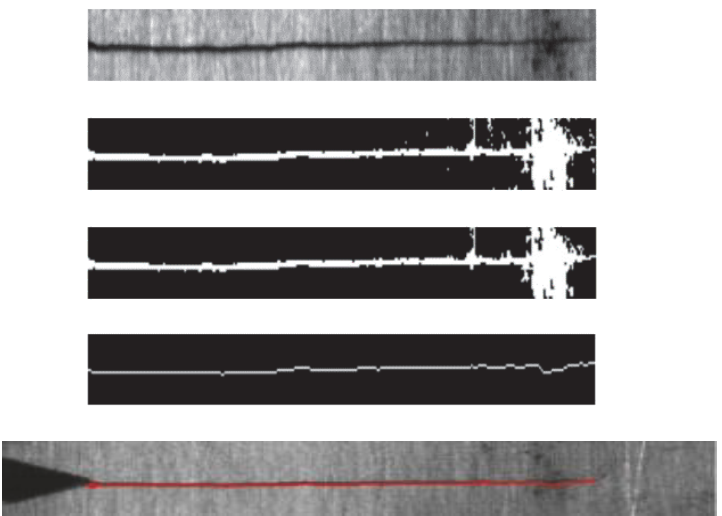

(d) Two kinds of crack length: $19.70 \mathrm{~mm}$ and $20.96 \mathrm{~mm}$
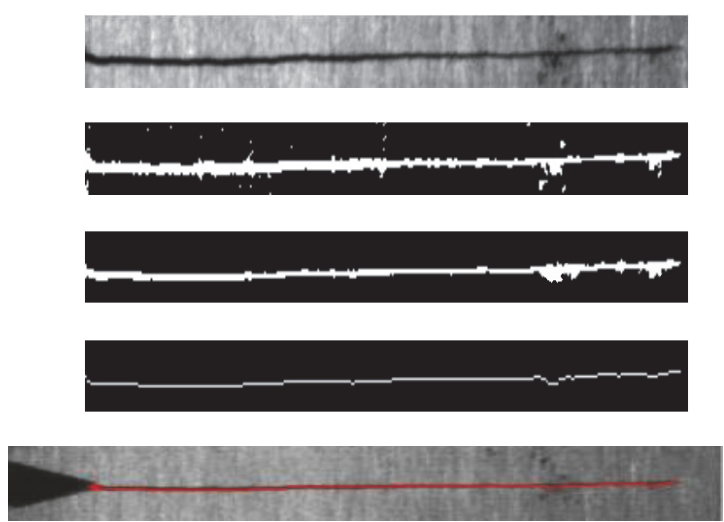

(e) Two kinds of crack length: $20.44 \mathrm{~mm}$ and $22.45 \mathrm{~mm}$

FIGURE 8: Result images in the process of crack extraction by the proposed method with different cracks length.

from Figure 11, the crack tip positions obtained by the two methods are very close, so the accuracy of the DIP method has been also verified in this way.

\subsection{Deformation Fields of Crack Tip Region within One Stress Cycle}

4.2.1. Measurement and Verification. In this section, in order to obtain deformation fields of crack tip region within one stress cycle, the reference image should be acquired after the specimen installation. During the FCG test, crack images are collected and the cracks length are obtained online in real time. When the crack grows to a certain length value, a series of specimen speckle images are collected in a short period of time, which are used as the target images for performing DIC operation to obtain the displacement and strain fields and further plastic zone size of crack tip region. A point in the crack tip elastic zone is taken as the feature point for data fitting and image matching, and then speckle images corresponding to characteristic load values within one stress cycle are obtained. Figure 11 shows the characteristic load 
TABLE 1: Comparative data of straight-line crack length.

\begin{tabular}{lccccccccccc}
\hline & 1 & 2 & 3 & 4 & 5 & 6 & 7 & 8 & 9 & 10 \\
\hline DIP $(\mathrm{mm})$ & 4.125 & 6.694 & 9.943 & 13.583 & 15.128 & 17.629 & 19.703 & 20.435 & 23.116 & 25.235 \\
Microscope $(\mathrm{mm})$ & 4.212 & 6.786 & 9.878 & 13.621 & 15.331 & 17.854 & 20.015 & 20.633 & 23.103 & 25.198 \\
Relative error \% & 2.066 & 1.356 & 0.455 & 0.352 & 0.152 & 0.311 & 0.112 & 0.059 & 0.056 & 0.103 \\
\hline
\end{tabular}

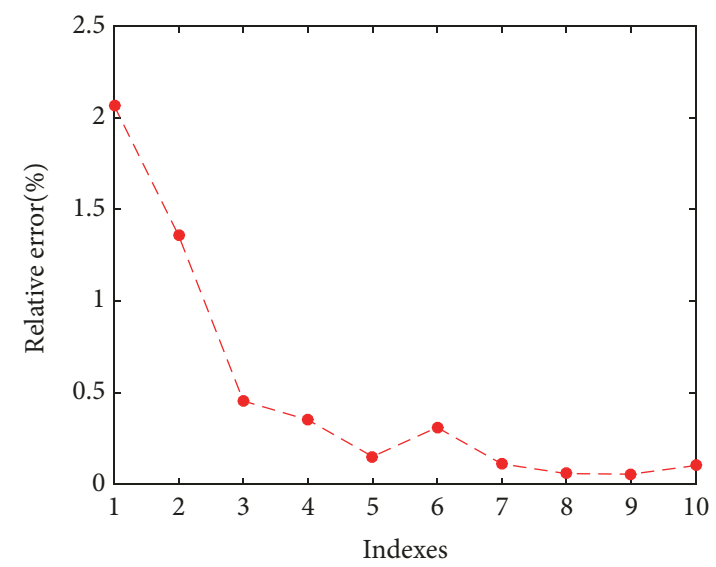

FIGURE 9: Relative errors of crack lengths.

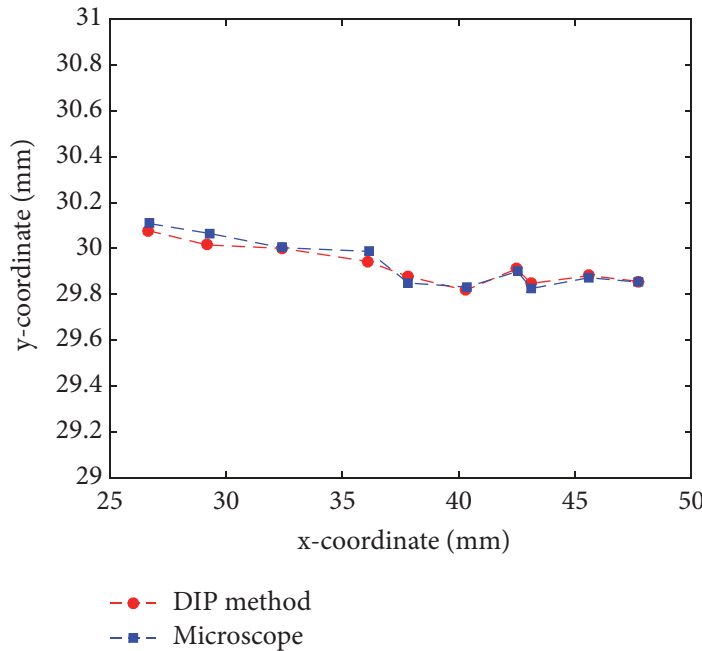

FIGURE 10: Comparison of crack tip positions measured by the two methods.

values within one stress cycle for the case that the crack length is $5.79 \mathrm{~mm}$ and the system resonant frequency is $125 \mathrm{~Hz}$, which are at $0,1 / 8 T, 1 / 4 T, 3 / 8 T, 1 / 2 T, 5 / 8 T, 6 / 8 T, 7 / 8 T$, and $T$ time instant.

Figures 12 and 13 show the Y-direction displacement and strain fields of crack tip ROI at the characteristic load values. In Figure 12, the displacement values in the lower part of the crack are greater than those in the upper zone. The reason is that the upper circular hole of the specimen is a fixed end, and the lower circular hole is subjected to a vertical downward tensile dynamic loading. Figure 14 shows the shape of crack tip plastic zone with $5.79 \mathrm{~mm}$ crack, and the size of plastic

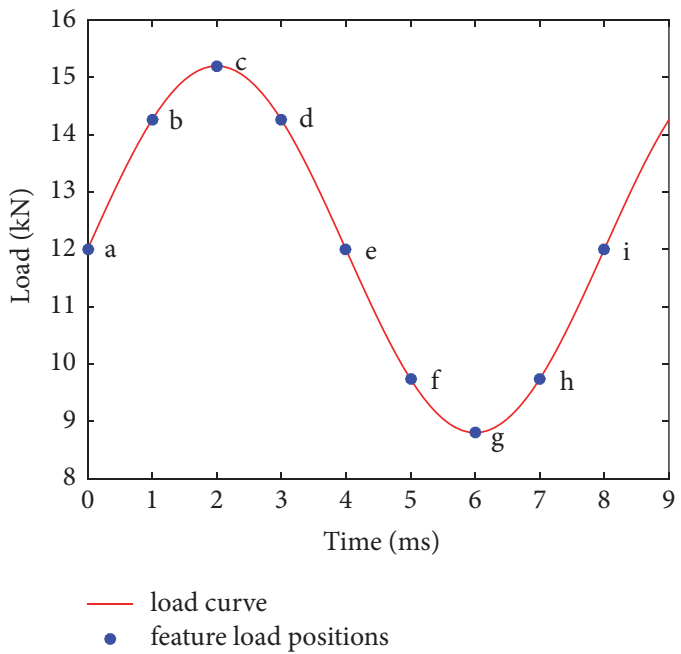

FIGURE 11: The characteristic load values within one stress cycle.

zone in the horizontal direction of the crack tip is about $0.38 \mathrm{~mm}$.

In this paper, the dynamic resistance strain indicator [33] is used to verify the strain value measured by DIC method. Within one stress cycle the strain values of feature point near the crack tip are obtained by these two methods and the strain curves are shown in Figure 15. Comparing the strain curves obtained by the two methods, they are in good agreement. It proves that the DIC method is accurate and feasible to calculate the strain of CT specimen in the crack tip region.

4.2.2. Results Discussions. Figures 16 and 17 show the displacement and strain values at the characteristic load values 


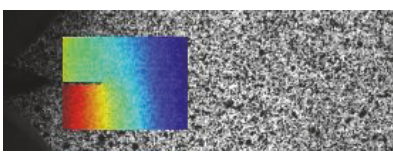

(a) $12.0 \mathrm{kN}$

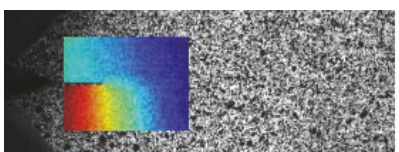

(d) $14.3 \mathrm{kN}$

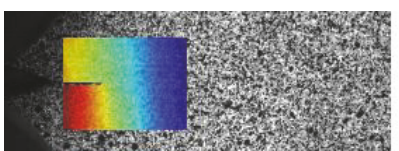

(g) $8.80 \mathrm{kN}$

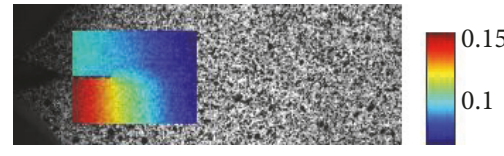

(b) $14.3 \mathrm{kN}$

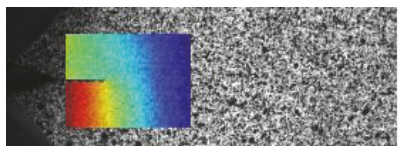

(e) $12.0 \mathrm{kN}$

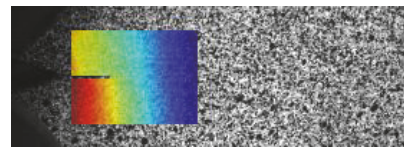

(h) $9.70 \mathrm{kN}$

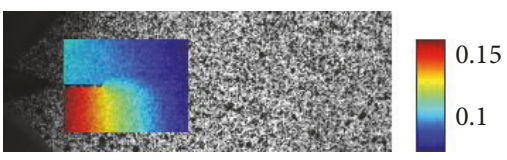

(c) $15.2 \mathrm{kN}$

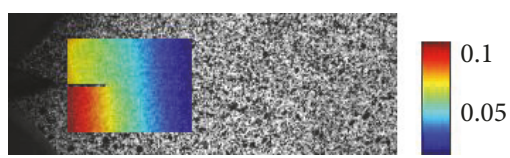

(f) $9.70 \mathrm{kN}$

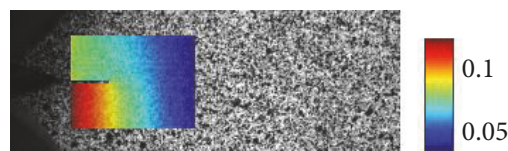

(i) $12.0 \mathrm{kN}$

FIGURE 12: Y-direction displacement fields at characteristic load values within one stress cycle with $5.79 \mathrm{~mm}$ crack.

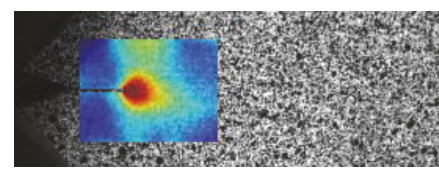

(a) $12.0 \mathrm{kN}$

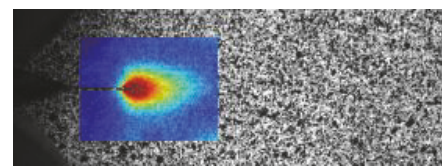

(d) $14.3 \mathrm{kN}$

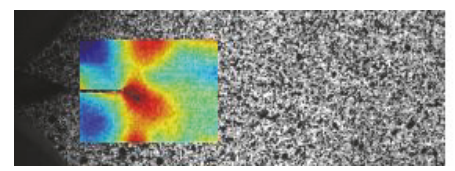

(g) $8.80 \mathrm{kN}$

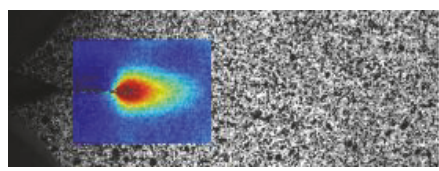

(b) $14.3 \mathrm{kN}$

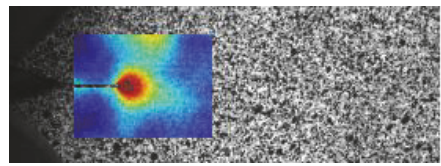

(e) $12.0 \mathrm{kN}$

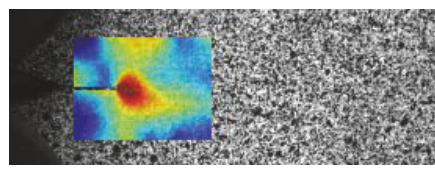

(h) $9.70 \mathrm{kN}$

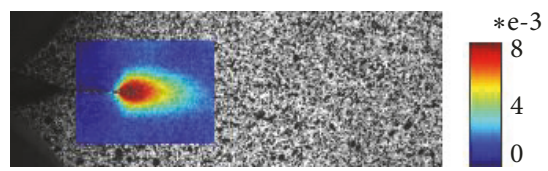

(c) $15.2 \mathrm{kN}$

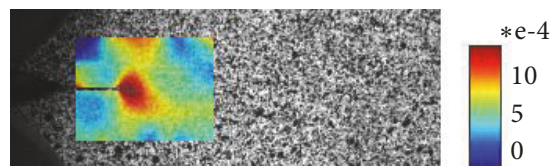

(f) $9.70 \mathrm{kN}$

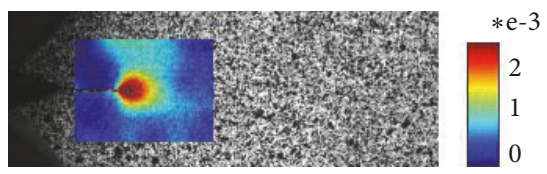

(i) $12.0 \mathrm{kN}$

FIGURE 13: Y-direction strain fields at characteristic load values within one stress cycle with $5.79 \mathrm{~mm}$ crack.

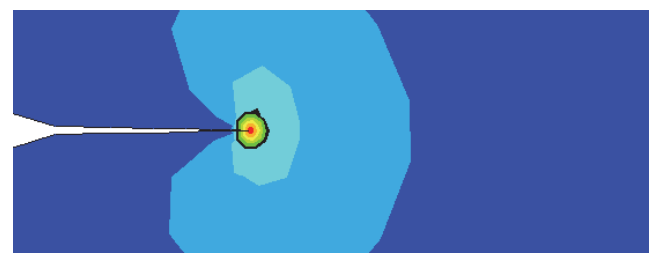

Figure 14: Plastic zone with 5.79mm cracks.

(shown in Figure 11) of the points at different positions from the crack tip along the horizontal direction of crack propagation, including the points in the plastic zone and elastic zone. As can be seen from Figure 16, the Y-direction displacement values in the ROI of the crack tip gradually decrease from left points to right points. This means that the closer the point to the crack tip is, the greater its displacement value is. As can be seen from Figure 17, due to stress concentration at the crack tip region, the maximum strain value in the strain fields is at the crack tip point and then the strain values rapidly decrease along the horizontal direction away from the crack tip. In the case of loading and unloading conditions with the same load value in one stress cycle, the displacement and strain values are slightly greater on the unloading condition than the corresponding values on the loading condition, as shown in the plots (b and d, f and h, 


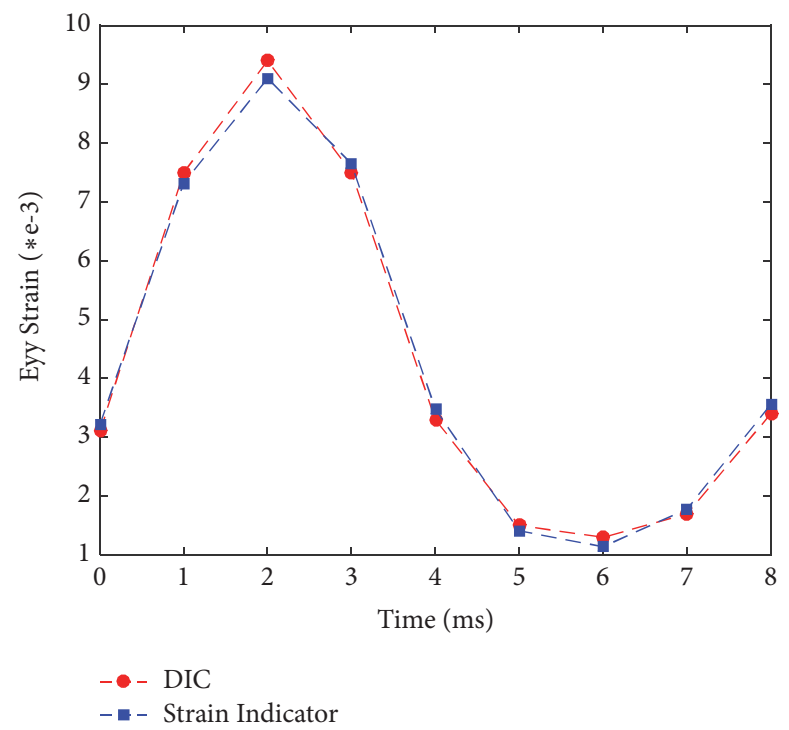

FIGURE 15: Measurement results obtained by DIC and strain indicator method.

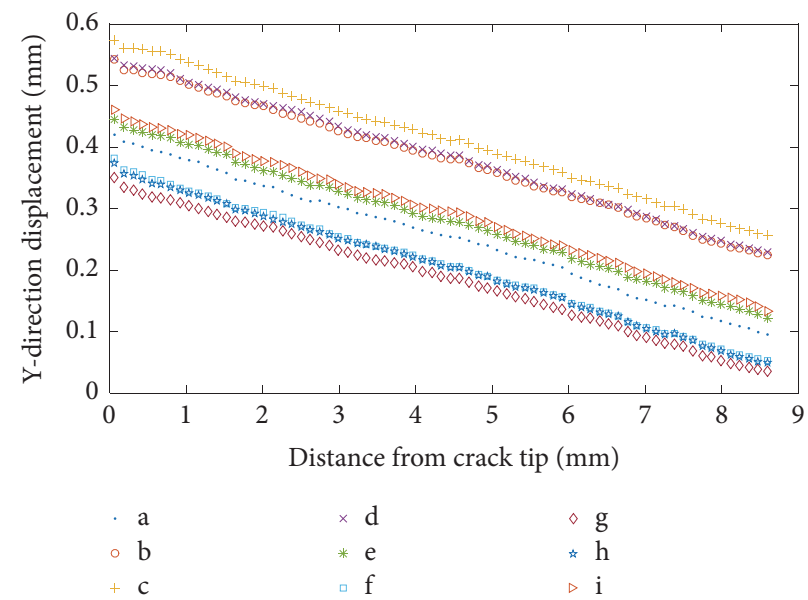

FIGURE 16: Displacements of points from the crack tip at characteristic load values within one stress cycle.

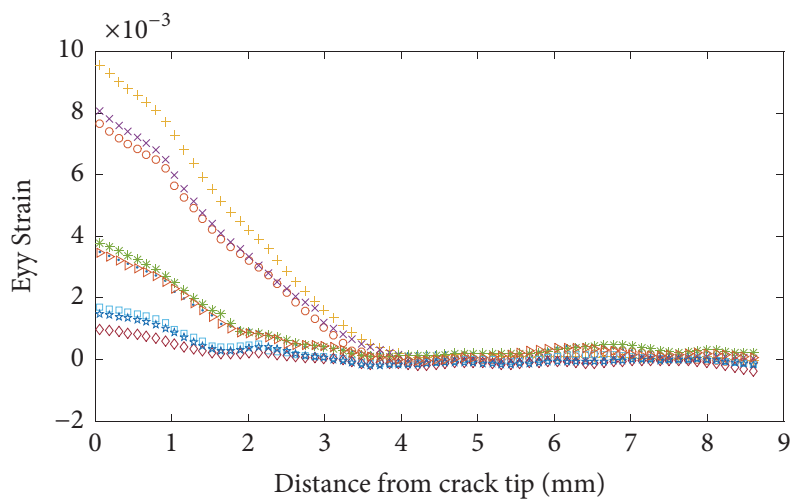

$\begin{array}{lll}\cdot \mathrm{a} & \times \mathrm{d} & \diamond \mathrm{g} \\ \circ \mathrm{b} & * \mathrm{e} & \neq \mathrm{h} \\ +\mathrm{c} & \square \mathrm{f} & \triangleright \mathrm{i}\end{array}$

FIGURE 17: Strains of points from the crack tip at characteristic load values within one stress cycle. 


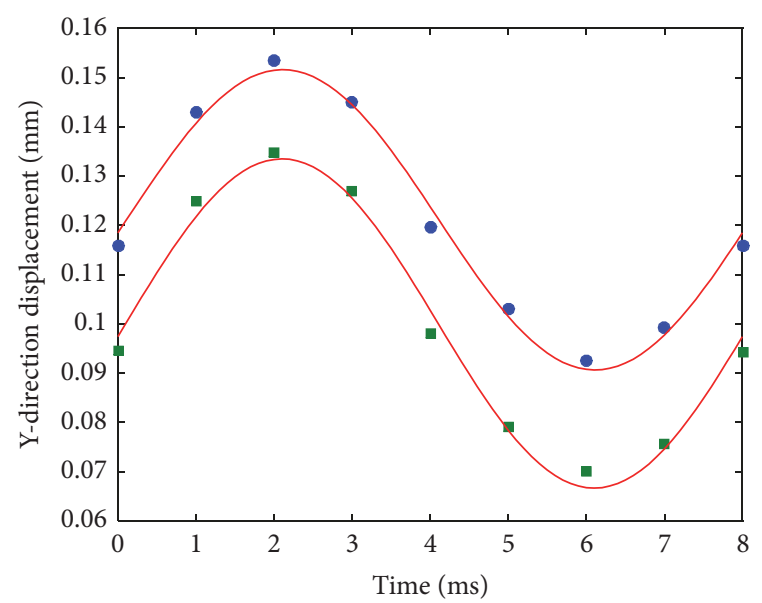

- $\mathrm{L}=0 \mathrm{~mm}$

- $\mathrm{L}=2 \mathrm{~mm}$

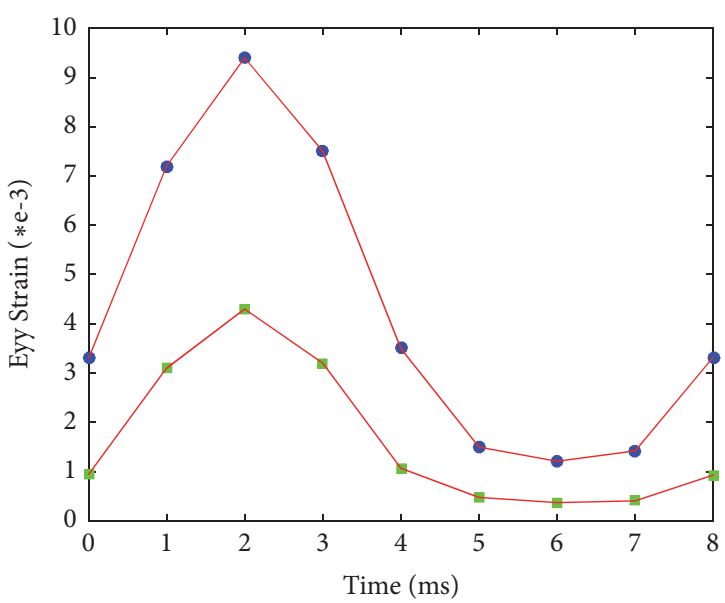

- $\mathrm{L}=0 \mathrm{~mm}$

- $\mathrm{L}=2 \mathrm{~mm}$

(a)

(b)

FIGURE 18: (a) Displacement curves of two points within one stress cycle; (b) strain curves of two points within one stress cycle.

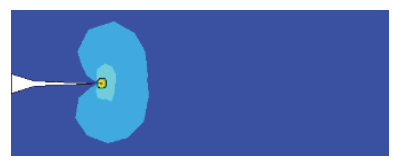

(a) Crack length $3.23 \mathrm{~mm}$ and radius of plastic zone $0.21 \mathrm{~mm}$

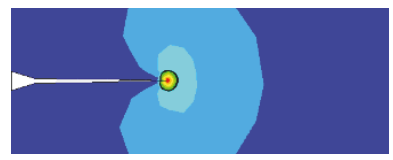

(b) Crack length $6.87 \mathrm{~mm}$ and radius of plastic zone $0.42 \mathrm{~mm}$

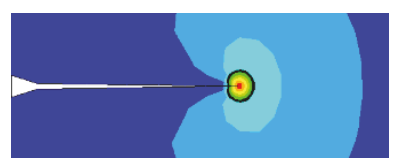

(c) Crack length $9.46 \mathrm{~mm}$ and radius of plastic zone $0.68 \mathrm{~mm}$

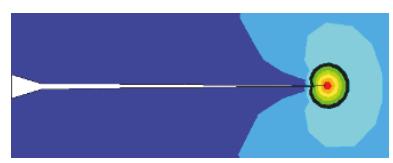

(d) Crack length $12.47 \mathrm{~mm}$ and radius of plastic zone $0.87 \mathrm{~mm}$

FIGURE 19: Plastic zone sizes with different cracks.

a, and e and i) in Figures 16 and 17, indicating that the material deformation hysteresis appeared in the fatigue test.

Within one stress cycle the displacement and strain values of the crack tip and feature point ( $2 \mathrm{~mm}$ away from the crack tip) are shown in Figures 18(a) and 18(b); the displacement curves of feature point and crack tip point are all the sinusoidal curves as the applied load.
4.3. The Plastic Zone Size of Crack Tip with Different Cracks. In this paper, the shape and size of plastic zone at the crack tip of CT specimen with different crack lengths are calculated using the proposed method after the cracks length, cracks tip position, and the speckle images corresponding to characteristic load values within one stress cycle have been obtained by the above proposed methods. The results are shown in Figure 19 where the plastic zones are surrounded 


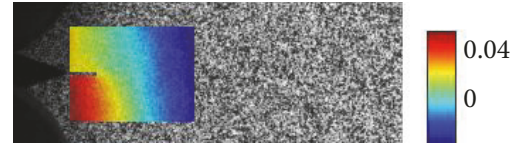

(a) $4.12 \mathrm{~mm}$

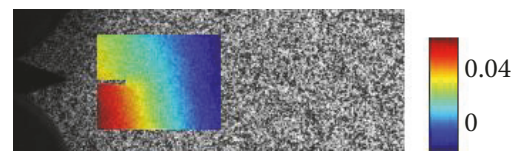

(d) $7.56 \mathrm{~mm}$

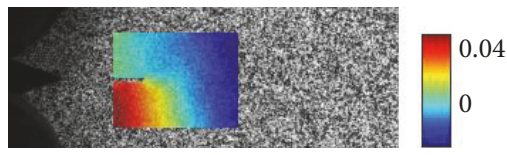

(g) $10.54 \mathrm{~mm}$

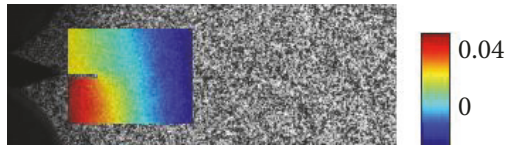

(b) $5.17 \mathrm{~mm}$

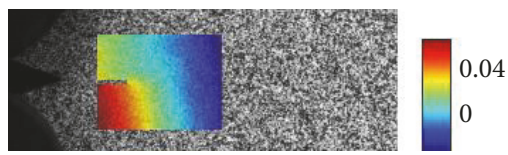

(e) $8.42 \mathrm{~mm}$

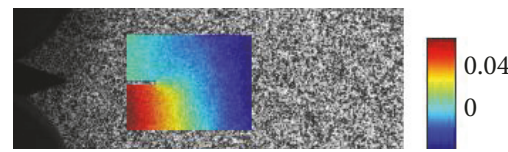

(h) $11.34 \mathrm{~mm}$

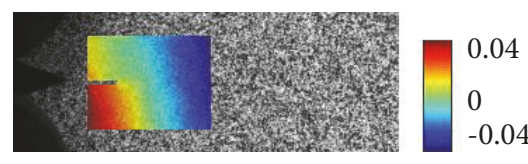

(c) $6.28 \mathrm{~mm}$

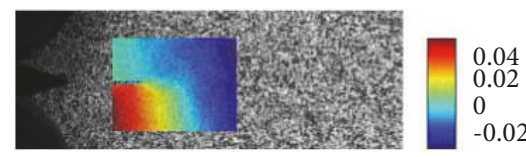

(f) $9.26 \mathrm{~mm}$

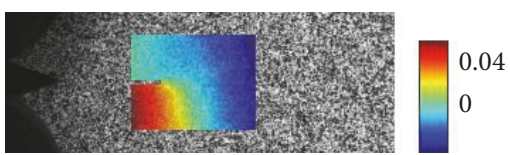

(i) $12.68 \mathrm{~mm}$

FIGURE 20: Y-direction displacement amplitude fields of crack tip region with different crack lengths.

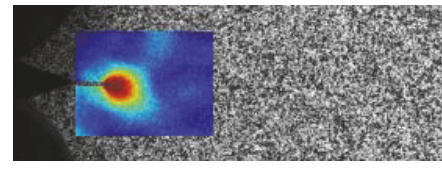

(a) $4.12 \mathrm{~mm}$

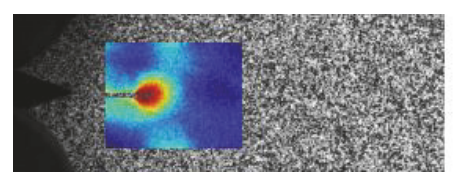

(d) $7.56 \mathrm{~mm}$

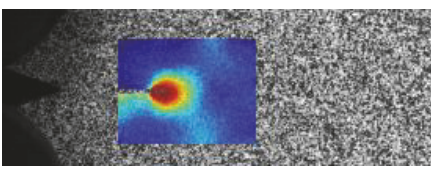

(g) $10.54 \mathrm{~mm}$
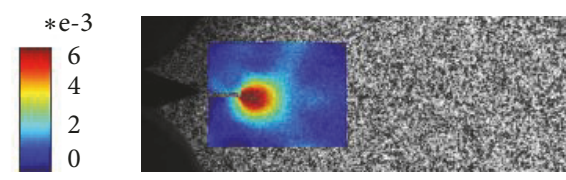

(b) $5.17 \mathrm{~mm}$
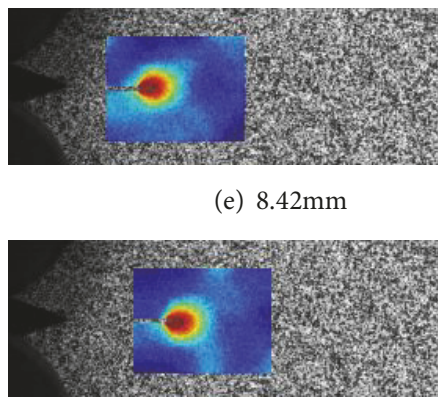

(h) $11.34 \mathrm{~mm}$

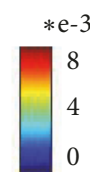

(e) $8.42 \mathrm{~mm}$
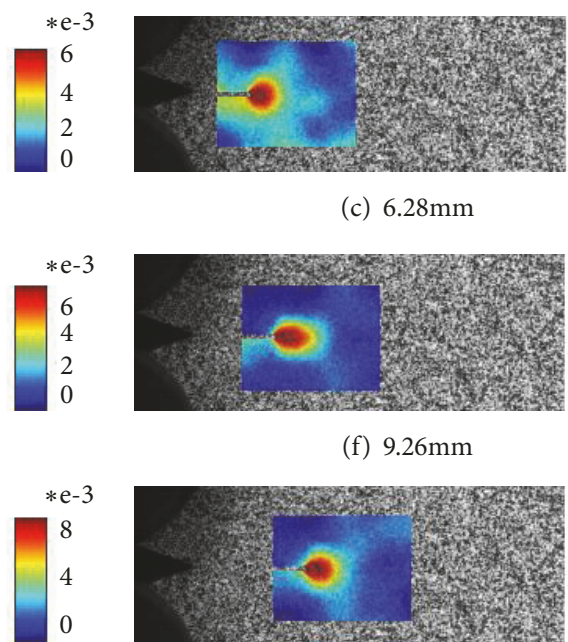

(i) $12.68 \mathrm{~mm}$

(c) $6.28 \mathrm{~mm}$

(f) $9.26 \mathrm{~mm}$
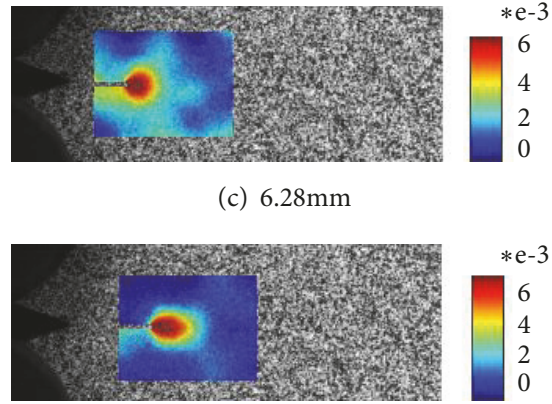

FIGURE 21: Y-direction strain amplitude fields of crack tip region with different crack lengths. by a black circle. As shown in Figure 19, the crack tip plastic zone size becomes larger with the fatigue crack propagation.

\subsection{Displacement and Strain Amplitude Fields of Crack Tip} Region with Different Cracks. In order to study the changing law of the displacement and strain amplitude fields of crack tip region with different crack lengths, the speckle images of specimen at the maximum and minimum load values in one stress cycle must be obtained by the proposed data fitting and image matching method. Figures 20 and 21 show the Ydirection displacement and strain amplitude fields of crack tip region when the crack grows from $4.12 \mathrm{~mm}$ to $12.68 \mathrm{~mm}$ in the FCG test.

The variation curves of displacement and strain amplitude of feature point which is close to the crack tip position with different crack lengths are shown in Figure 22. As can be seen from Figure 22, the displacement and strain amplitude values of the feature point increase with the growth of the crack length. From 4.12 to $7.56 \mathrm{~mm}$, the crack propagation is slow and the displacement and strain amplitude values are stable. When the crack grows to about $8.42 \mathrm{~mm}$, the crack propagation rate increases rapidly, and the displacement and strain amplitude values also increase significantly. The measurement results show that the larger the fatigue crack length is, the larger the displacement and strain amplitude values at the crack tip region are and the faster the crack propagation rate is.

\section{Conclusion}

In this paper, a novel hybrid image processing method based on the combination of DIP method, DIC method, and digital high-speed photography is proposed for measuring the crack length, crack tip location, propagation path, the displacement and strain fields, and plastic zone size of crack tip region under high-frequency resonant loading. The accuracy and 


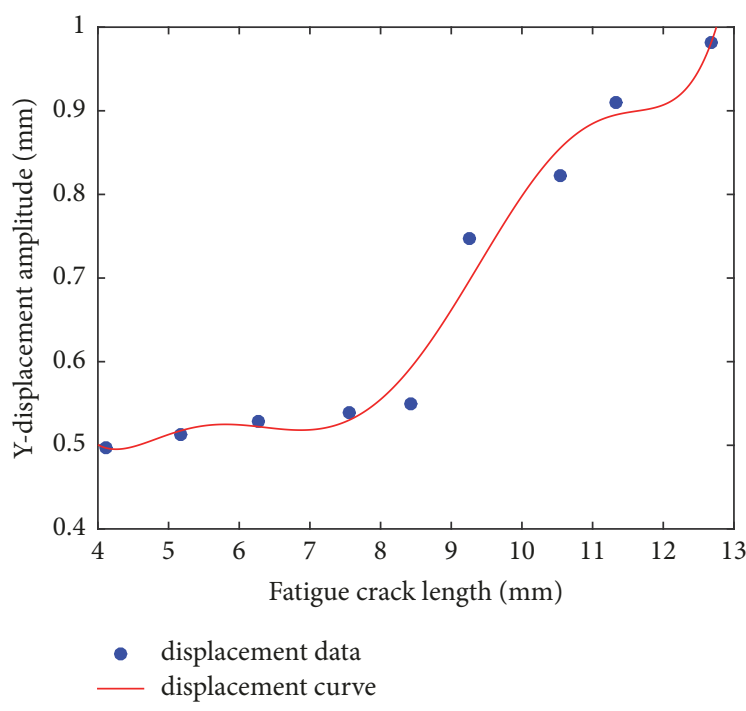

(a)

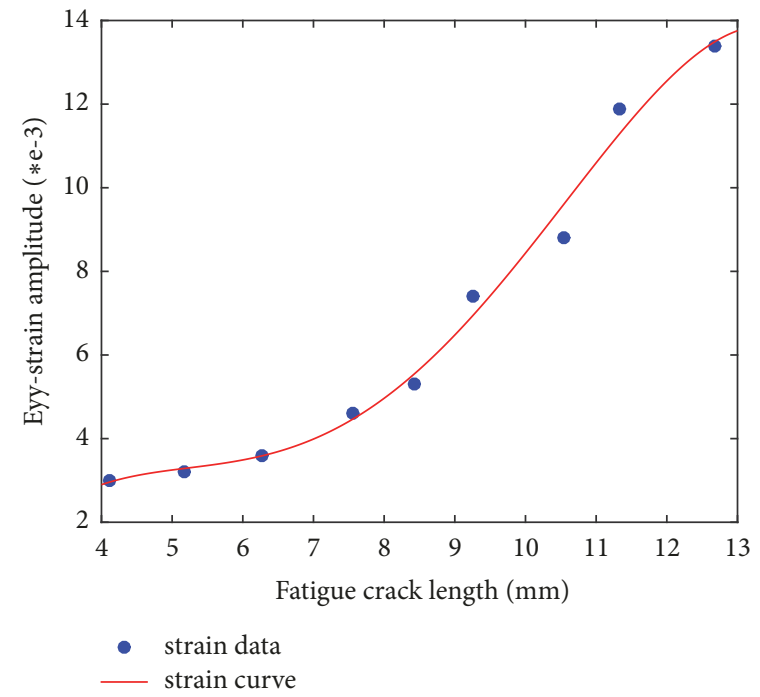

(b)

FIGURE 22: (a) Relationship between crack length and Y-direction displacement amplitude of feature point. (b) Relationship between crack length and Y-direction strain amplitude of feature point.

feasibility of this method are proved by the ordinary methods. The research results show that the crack length and crack tip position can be measured precisely by the proposed online measuring method based on DIP; the crack tip plastic zone with different crack lengths can be estimated and the size of the plastic zone becomes larger with the crack propagation; by the proposed image matching method, the speckle images of a CT specimen subjected to high-frequency resonant loading corresponding to characteristic load points within one stress cycle can be obtained; accordingly, the displacement and strain fields of crack tip region within one stress cycle and the displacement and strain amplitude fields with different crack lengths are all obtained under this kind of loading condition; the fatigue crack tip stress concentration, material deformation hysteresis, the Y-direction displacement, and strain amplitude of crack tip feature point have also been analyzed, and they achieved good results. The success of this method can help to obtain better insight into and understanding of the fatigue and failure behavior of material with mode I crack under high-frequency resonant loading.

\section{Conflicts of Interest}

The authors confirm that this article content has no conflicts of interest.

\section{Acknowledgments}

This work is supported by grants from National Natural Science Foundation of China, Grant no. 51375445.

\section{References}

[1] M. D. Sangid, "The physics of fatigue crack initiation," International Journal of Fatigue, vol. 57, pp. 58-72, 2013.
[2] J. K. Sahu, U. Krupp, and H.-J. Christ, "Fatigue crack initiation behavior in embrittled austenitic-ferritic stainless steel," International Journal of Fatigue, vol. 45, pp. 8-14, 2012.

[3] C. Navarro, J. Vázquez, and J. Domínguez, "3D vs. 2D fatigue crack initiation and propagation in notched plates," International Journal of Fatigue, vol. 58, pp. 40-46, 2014.

[4] M. Giglio and A. Manes, "Crack propagation on helicopter panel: Experimental test and analysis," Engineering Fracture Mechanics, vol. 75, no. 3-4, pp. 866-879, 2008.

[5] H.-Y. Qi, W.-D. Wen, and L.-W. Sun, "Fatigue life prediction and experiment research for composite laminates with circular hole," Journal of Central South University of Technology (English Edition), vol. 11, no. 1, pp. 19-22, 2004.

[6] P. Lorenzino and A. Navarro, "The variation of resonance frequency in fatigue tests as a tool for in-situ identification of crack initiation and propagation, and for the determination of cracked areas," International Journal of Fatigue, vol. 70, pp. 374382, 2015.

[7] L. Witek, "Simulation of crack growth in the compressor blade subjected to resonant vibration using hybrid method," Engineering Failure Analysis, vol. 49, pp. 57-66, 2015.

[8] M. Budnitzkia, M. C. Scates, and R. O. Ritchie, "The effects of cubic stiffness on fatigue characterization resonator performance," Sensors Actuators A Physical, vol. 157, no. 2, pp. 228-234, 2010.

[9] C. L. Muhlstein, R. T. Howe, and R. O. Ritchie, "Fatigue of polycrystalline silicon for microelectromechanical system applications: Crack growth and stability under resonant loading conditions," Mechanics of Materials, vol. 36, no. 1-2, pp. 13-33, 2004.

[10] A. Walcker, D. Weygand, and O. Kraft, "Inertial effects on dislocation damping under cyclic loading with ultra-high frequencies," Materials Science and Engineering: A Structural Materials: Properties, Microstructure and Processing, vol. 400-401, no. 1-2, pp. 397-400, 2005.

[11] A. V. Amirkhizi, A. Tehranian, and S. Nemat-Nasser, "Stresswave energy management through material anisotropy," Wave Motion, vol. 47, no. 8, pp. 519-536, 2010. 
[12] R. Goel, M. D. Kulkarni, K. S. Pandya, and N. K. Naik, "Stress wave micro-macro attenuation in ceramic plates made of tiles during ballistic impact," International Journal of Mechanical Sciences, vol. 83, pp. 30-37, 2014.

[13] B. Pan, K. Qian, H. Xie, and A. Asundi, "Two-dimensional digital image correlation for in-plane displacement and strain measurement: a review," Measurement Science and Technology, vol. 20, no. 6, Article ID 062001, 2009.

[14] X. Dai, F. Yang, L. Wang, D. Zhang, Q. Pu, and X. He, "Load capacity evaluated from fracture initiation and onset of rapid propagation for cast iron by digital image correlation," Optics and Lasers in Engineering, vol. 51, no. 9, pp. 1092-1101, 2013.

[15] Z. Lei, R. Bai, L. Deng, and W. Qiu, "Noncontact optical measurement of CTOA and CTOD for interface crack in DCB test," Optics and Lasers in Engineering, vol. 50, no. 7, pp. 964-970, 2012.

[16] R. Kulkarni, S. S. Gorthi, and P. Rastogi, "Measurement of inplane and out-of-plane displacements and strains using digital holographic moiré," Journal of Modern Optics, vol. 61, no. 9, pp. 755-762, 2014.

[17] L. J. Fellows and D. Nowell, "Measurement of crack closure after the application of an overload cycle, using moiré interferometry," International Journal of Fatigue, vol. 27, no. 10-12, pp. 14531462, 2005.

[18] M. V. Matham and N. Sujatha, "Digital speckle pattern interferometry for deformation analysis of inner surfaces of cylindrical specimens," Applied Optics, vol. 43, no. 12, pp. 2400-2408, 2004.

[19] X. Dai, Q. Pu, L. Wang, H. Yun, and Y. Wang, "Measurement on fracture process and prediction of the load capacity of steel fiber reinforced concrete by electronic speckle pattern interferometry," Composites Part B: Engineering, vol. 42, no. 5, pp. 1181-1188, 2011.

[20] R. Bedsole and H. V. Tippur, "Dynamic fracture characterization of small specimens: A study of loading rate effects on acrylic and acrylic bone cement," Journal of Engineering Materials and Technology, vol. 135, no. 3, Article ID 031001, 2013.

[21] K. C. Jajam and H. V. Tippur, "An experimental investigation of dynamic crack growth past a stiff inclusion," Engineering Fracture Mechanics, vol. 78, no. 6, pp. 1289-1305, 2011.

[22] S. Vanlanduit, J. Vanherzeele, R. Longo, and P. Guillaume, "A digital image correlation method for fatigue test experiments," Optics and Lasers in Engineering, vol. 47, no. 3-4, pp. 371-378, 2009.

[23] M. Poncelet, G. Barbier, B. Raka et al., "Biaxial high cycle fatigue of a type 304L stainless steel: Cyclic strains and crack initiation detection by digital image correlation," European Journal of Mechanics - A/Solids, vol. 29, no. 5, pp. 810-825, 2010.

[24] F. Mathieu and F. Hild, "Identification of a crack propagation law by digital image correlation," International Journal of Fatigue, vol. 36, no. 1, pp. 146-154, 2012.

[25] J. Réthoré, F. Hild, and S. Roux, "Extended digital image correlation with crack shape optimization," International Journal for Numerical Methods in Engineering, vol. 73, no. 2, pp. 248-272, 2008.

[26] E. Fagerholt, T. Borvik, and O. S. Hopperstad, "Measuring discontinuous displacement fields in cracked specimens using digital image correlation with mesh adaptation and crack-path optimization," Optics and Lasers in Engineering, vol. 51, no. 3, pp. 299-310, 2013.

[27] J. L. Chen, N. Zhan, X. C. Zhang, and J. X. Wang, "Improved extended digital image correlation for crack tip deformation measurement," Optics and Lasers in Engineering, vol. 65, pp. 103-109, 2015.

[28] P. J. Tavares, N. Viriato, A. P. Vaz, and P. M. G. P. Moreira, "A dedicated illumination system for fatigue crack-growth measurement," Measurement, vol. 90, pp. 85-93, 2016.

[29] W. Cai and J. Bisschop, "Optical method for measuring slow crack growth in cementitious materials," Materials and Structures/Materiaux et Constructions, vol. 45, no. 11, pp. 1613-1623, 2012.

[30] W. Withayachumnankul, P. Kunakornvong, C. Asavathongkul, and P. Sooraksa, "Rapid detection of hairline cracks on the surface of piezoelectric ceramics," The International Journal of Advanced Manufacturing Technology, vol. 64, no. 9-12, pp. 12751283, 2013.

[31] J. Blaber, B. Adair, and A. Antoniou, "Ncorr: Open-Source 2D Digital Image Correlation Matlab Software," Experimental Mechanics, vol. 55, no. 6, pp. 1105-1122, 2015.

[32] J. M. Vasco-Olmo et al., "Assessment of crack tip plastic zone size and shape and its influence on crack tip shielding," Fatigue \& Fracture of Engineering Materials \& Structures, vol. 39, no. 8, pp. 969-981, 2016.

[33] D. Chakraborty, K. S. R. K. Murthy, and D. Chakraborty, "A new single strain gage technique for the accurate determination of mode I stress intensity factor in orthotropic composite materials," Engineering Fracture Mechanics, pp. 142-154, 2014. 


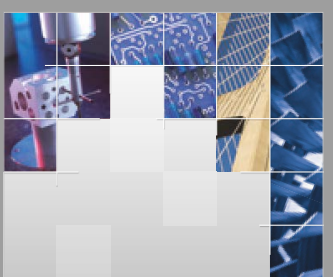

\section{Enfincering}
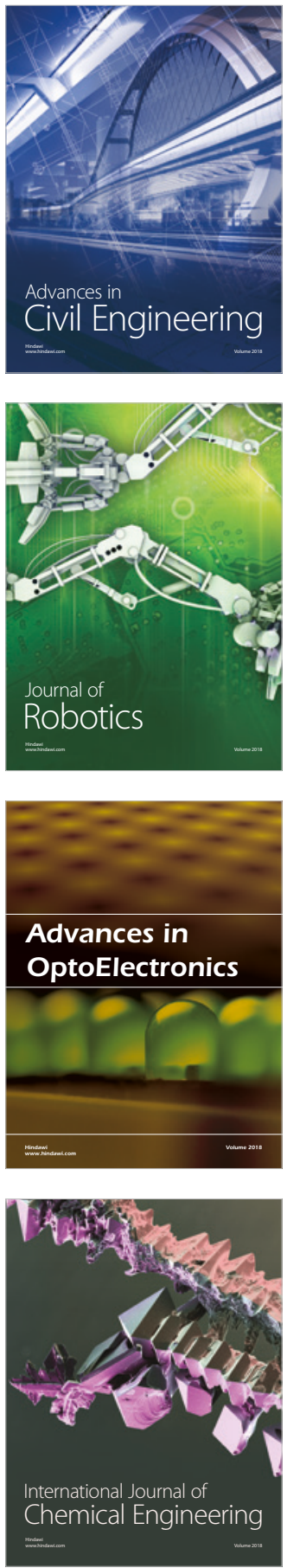

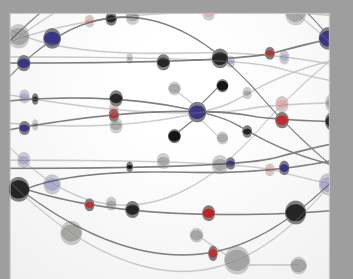

\section{Rotating \\ Machinery}

The Scientific World Journal

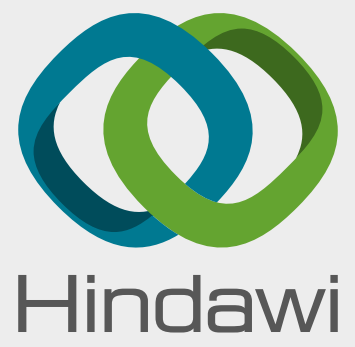

Submit your manuscripts at

www.hindawi.com
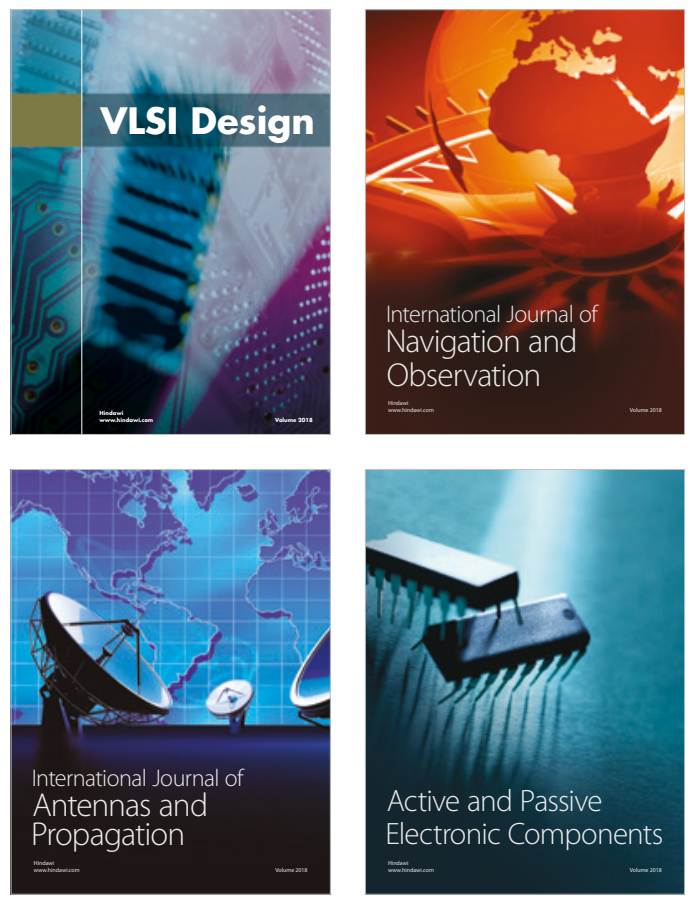
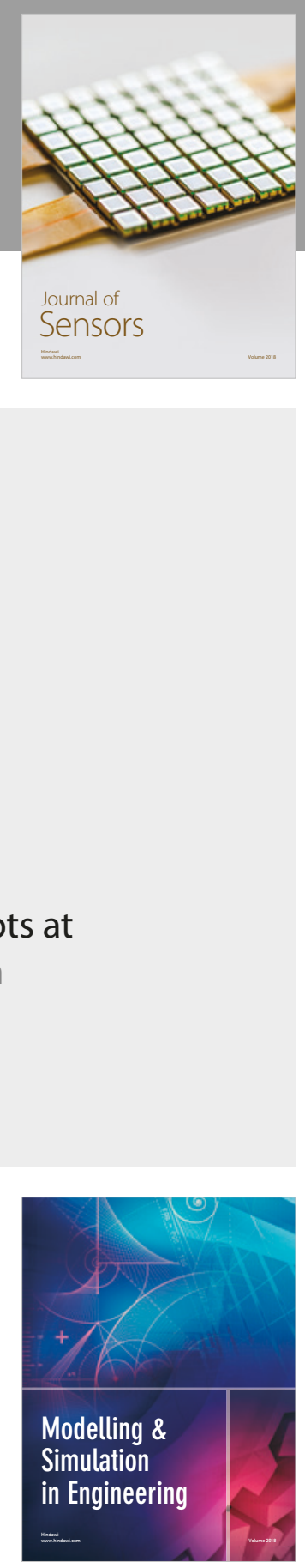

\section{Advances \\ Multimedia}
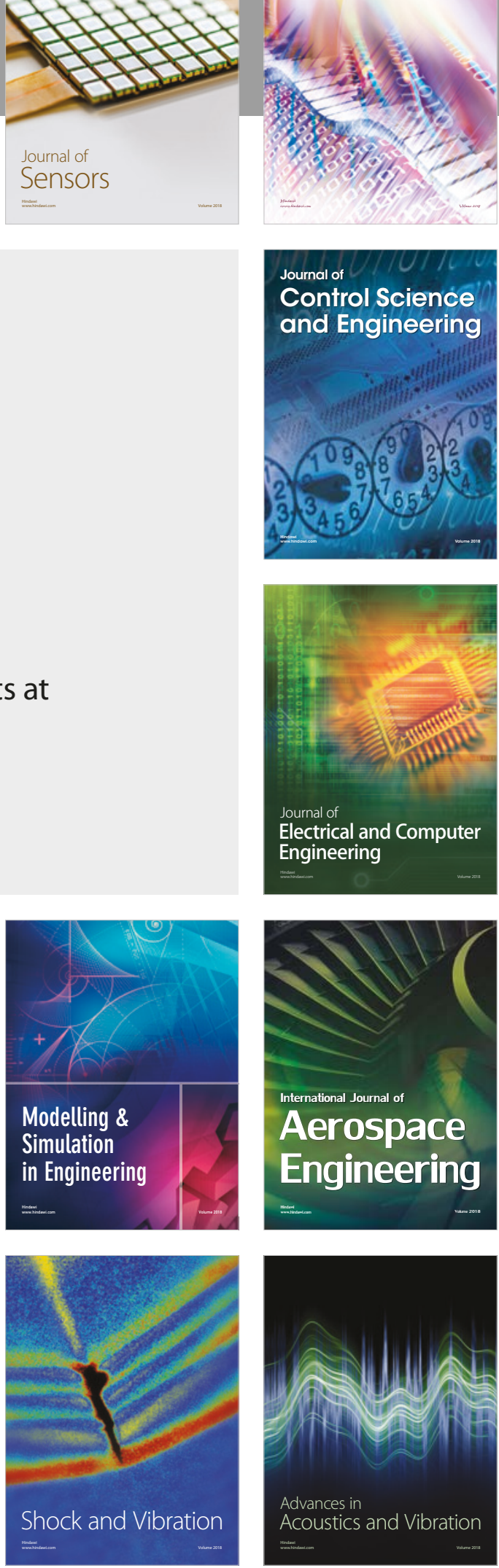